\title{
Simulation Model to Determine Ratios between Quay, Yard and Intra-Terminal Transfer Equipment in an Integrated Container Handling System
}

Author(s): Mei Sha, Theo Notteboom, Tao Zhang, Xin Zhou, Tianbao Qin

Source: Journal of International Logistics and Trade 2021; 19(1):1-18

Published by: Jungseok Research Institute of International Logistics and Trade, Inha University

DOI: https://doi.org/10.24006/jilt. 2021.19.1.001

Journal of International Logistics and Trade is an official journal published by Jungseok Research Institute of International Logistics and Trade, Inha University, Korea. JILT welcomes manuscripts that advance the practice and science of logistics, trade, and other related fields.

Frequency: Quarterly (March, June, September, December)

Stable URL: https://www.ejilt.org

Jungseok Research Institute of International Logistics and Trade is a specialized academic research institute representing Inha University and Inha Foundation in Korea. The institute aims to become a representative institute in Northeast Asia in the research of logistics and trade.

Stable URL: https://jrieng.inha.ac.kr

(C) Copyright. Jungseok Research Institute of International Logistics and Trade.

This is an Open-Access article distributed under the terms of the Creative Commons Attribution NonCommercial License (http://creativecommons.org/licenses/by-nc/4.0/) which permits unrestricted noncommercial use, distribution, and reproduction in any medium, provided the original work is properly cited 


\title{
ARTICLE
}

\section{Simulation Model to Determine Ratios between Quay, Yard and Intra- Terminal Transfer Equipment in an Integrated Container Handling System}

\author{
Mei Sha ${ }^{1}$, Theo Notteboom ${ }^{2,3,}{ }^{*}$, Tao Zhang ${ }^{1}$, Xin Zhou ${ }^{2}$, Tianbao Qin ${ }^{1}$ \\ ${ }^{1}$ Logistics Management Specialty, Management Department of Shanghai Maritime University, Shanghai 200135, China \\ ${ }^{2}$ Center for Eurasian Maritime and Inland Logistics (CEMIL), China Institute of FTZ Supply Chain, Shanghai Maritime University, Shanghai 200135, China \\ ${ }^{3}$ Maritime Institute, Faculty of Law and Criminology, Ghent University, Ghent 9000, Belgium
}

$\begin{array}{ll}\text { Received } & \text { June 02, } 2020 \\ \text { Revised } & \text { September 17, } 2020 \\ \text { Accepted } & \text { January 05, } 2021 \\ & \\ & \\ \text { *Corresponding author: Theo Notteboom } \\ \text { Center for Eurasian Maritime and Inland } \\ \text { Logistics (CEMIL), China Institute of FTZ } \\ \text { Supply Chain, Shanghai Maritime } \\ \text { University, Shanghai 200135, China } \\ \text { Tel: +86-2138282000 } \\ \text { Fax: +86-2138284166 } \\ \text { E-mail: theo.notteboom@shmtu.edu.cn }\end{array}$

Received June 02, 2020

Revised September 17, 2020

E-mail: theo.notteboom@shmtu.edu.cn

\begin{abstract}
This paper presents a generic simulation model to determine the equipment mix (quay, yard and intra-terminal transfer) for a Container Terminal Logistics Operations System (CTLOS). The simulation model for the CTLOS, a typical type of discrete event dynamic system (DEDS), consists of three sub-models: ship queue, loading-unloading operations and yard-gate operations. The simulation model is empirically applied to phase 1 of the Yangshan Deep Water Port in Shanghai. This study considers different scenarios in terms of container throughput levels, equipment utilization rates, and operational bottlenecks, and presents a sensitivity analysis to evaluate and choose reasonable equipment ratio ranges under different operational conditions.
\end{abstract}

Keywords Container terminal, Logistics operations system, Simulation modeling, Handling system, Discrete event dynamic system

\section{Introduction}

Containerization is a key enabler of economic globalization (for a quantitative approach: Bernhofen et al. 2016; for a qualitative one: Levinson, 2016) and the adoption of new supply chain practices (Fransoo and Lee, 2013; Notteboom and Rodrigue, 2009). Container terminal facilities act as sea-sea and sea-land nodes in global containerized supply chains. The important role of container terminals in the global transport and logistics system has triggered a process towards a 'terminalization' of supply chains (Rodrigue and Notteboom, 2009) driven by efficiency, chain synchronization and coordination. The ever-growing container volumes and vessel sizes of up to 24,000 TEU (Ge et al. 2019) challenge terminals to optimize terminal operations and to maximize productivity at the quayside, on the yard and in the connection to the hinterland. The choice of terminal equipment and the day-to-day deployment and allocation of the equipment mix are fundamental in view of achieving a high terminal productivity and a better integration of the terminal in global supply chains passing through the facility.

Most terminal operation studies in extant literature refer to only one type of handling equipment or one part of the terminal operating system (i.e., quay, yard or intra-terminal vehicles). Consequently, the planning decisions may end up being suboptimal and the efficiency improvements may not be as significant compared to a more integrated scheduling approach. In recent years, an increasing number of studies developed a more integrated view on container terminal optimization by combining quay-related with yard-related planning problems. This paper contributes to this research stream by using simulation techniques to solve a specific problem in terminal development and management, i.e. the determination of the ratios of the main equipment used in an integrated container handling system. The presented simulation focuses on a common terminal equipment mix combining quay cranes (QC) for quay operations, rubber-tired gantry cranes (RTG) for yard/stacking operations and intraterminal trucks/trailers (ITT) for intra-terminal transfers, although the methodology can also be applied to other equipment setups.

The remainder of the paper is organized as follows. The next section provides a literature review in order to position our research in extant literature. Then, we introduce the problem statement. Sections 4 and 5 present the multi-layered simulation model. In section 6, we set up a simulation experiment to study a real case using data from terminals in the port of Shanghai. Finally, section 7 summarizes our findings and draws relevant conclusions. 


\section{Literature review: an integrated view on container terminal optimization}

Extant literature on container terminal operations and optimization focuses on a range of issues related to the quayside, the yard and land access (for an overview see e.g. Steenken et al. 2004 and Stahlbock and Voß, 2008).

First, ship or quay-related operational challenges include the berth allocation problem (BAP), the stowage planning problem and the QC assignment/scheduling problem (QCAP). Quite a few studies combine several quay-related planning issues. Yang et al., (2012) present an optimization approach for coupling the berth allocation and quay crane assignment problems (BACAPs). Iris et al. (2015) advance the study of the integrated BACAP in seaport container terminals by proposing novel set partitioning models. Zhen et al. (2017) advanced research on simultaneous berth and QC planning (allocation and operation) by developing an integer programming model that also considers tides and channel flow control constraints. Cho et al. (2020) integrate a filtered beam search (FBS)-based heuristic, a greedy randomized adaptive search procedure (GRASP)-based heuristic, and an iterative approach to solve BACAP in a multi-user container terminal. Other recent work applying advanced heuristics on BACAP include Abou Kasm et al. (2020), Agra and Oliviera (2018), Iris et al. (2017), Li et al. (2019), and Malekahmadi et al. (2020). Wang et al. (2020) study BACAP with the consideration of carbon emission taxation.

Second, a broad range of studies focuses on yard-related optimization and scheduling, i.e., the yard allocation problem (YAP), such as the design of the stacking area (in terms of stacking height, slot capacity, etc.) or the optimization of container storage and stacking operations as a function of container type (reefer, dry, etc.), container flow (import, export, T/S, empties) and dwell time characteristics. Yard-related research also deals with intra-terminal transport such as the transport between the quayside and the stacking area and the intra-terminal reshuffling of containers, see e.g. Chen and Lu (2012), Jin et al. (2016) and Zhen et al. (2016). More recently, Razouk et al. (2019) developed an adapted bin packing algorithm of the yard optimization problem considering three important components: unloading/loading, transfer and the storage process. Zhou et al. (2020a) propose an integrated optimization approach for simultaneously determining the yard crane schedules and the vehicle parking positions, while Zhou et al. (2020b) present a simulation optimization iteration approach to integrate YAP with the vehicle congestion problem.

Third, terminal operations research also focuses on the connectivity of terminals to landside transportation modes, i.e., rail transport, inland barges and trucking. Typical research themes in this field include the truck gate process optimization problem, gate appointment systems, the equipment assignment problem and the spatial and temporal separation of transport modes on a terminal, see Zhang et al. (2019) and Azab et al. (2020) for an overview.

While the above studies have their merits, they do not address the integrated scheduling of different types of handling equipment, such as the combination of QC, RTG, and ITT. In the past decade, an increasing number of studies developed a more integrated view on container terminal optimization, often relying on simulation approaches to analyze terminal operations from a more system-based perspective combining BAP/QCAP/BACAP with YAP. The extensive literature analysis of simulation-based studies in Dragović et al. (2016) shows that discrete-event simulation remains one of the most popular techniques in port operations modelling. Other techniques have been used such as agent-based modelling, network-based modelling, simulation-based education, web-based simulation, etc. Chen et al. (2007) developed an integrated model to schedule different types of handling equipment in a container terminal, which was formulated as a Hybrid Flow Shop Scheduling problem and solved by a tabu search algorithm. Zeng and Yang (2009) proposed a simulation-based optimization approach to solve an integrated handling equipment scheduling problem for loading operations. Cao et al. (2010) proposed an integrated model for ITT and yard crane scheduling problems for loading operations at a container terminal. The problem was formulated as a MIP model. Chen et al. (2013) developed a constraint programming model to address integrated scheduling of crane handling and truck transportation, and proposed a three-stage algorithm to solve the model. Tang et al. (2014) dealt with the joint QC and truck scheduling problem in view of reducing the idle time of equipment. Assadipour et al. (2014) provided an analytical framework for efficient integrated scheduling of QCs and yard cranes, to minimize the container cycle time. He et al. (2015) deal with the integrated scheduling problem for QCs, ITTs and yard cranes. More recently, Iris et al. (2018) used a heuristic algorithm to address the integrated management of vessel loading operations and the planning of yard vehicles, thereby considering the specifications of operational agreements between terminal operators and liner shipping companies. Wang et al. (2018) apply a mixed integer linear programming model to optimize the three main types of resources used in container terminals: berths, QCs, and yard storage space. In addition, they developed a column generation (CG) procedure to provide a lower bound for the integrated problem. Liu (2020) studies simultaneous allocations of berths, QCs, and yards in transshipment hubs using a mixed-integer programming model. An iterative heuristic is developed to solve the proposed model. 


\section{Problem statement}

We present a simulation approach for the integrated determination of the ratios between different types of handling equipment. More in particular, we present a model to obtain an optimal combination of QCs, RTGs, and ITTs in the context of the Container Terminal Logistics Operations System (CTLOS) and apply this model to a terminal in the port of Shanghai. The CTLOS involves the planning, organization and control of the operating processes and operating activities linked to the inputs, transformations and outputs in the Container Terminal Logistics System or CTLS (Figure 1). This research can thus be positioned in the research stream on integrated terminal equipment planning combining quay and yard-related scheduling problems. The determination of optimal equipment ratios is a key decision in terminal development and management. The choices of ratios made will result in specific numbers of quay and yard equipment to be used on the terminal and thus strongly shapes integrated berth and yard scheduling problems associated with the chosen equipment mix.

Table 1 provides an overview of the available equipment options for ship-to-shore operations, stacking operations on the yard and the intra-terminal transfers of containers. By combining specific quay, yard and intra-terminal transport equipment, operators obtain an equipment mix setup of a terminal facility. Table 1 also provides some examples from around the world on possible combinations of equipment options (quay, yard, and intra-terminal transport). The equipment mix and the ratios between quay, yard and intra-terminal vehicles will have an impact on the characteristics of the CTLS which is the integrated system that consists of the following inter-related and interacting entities: containers, ships, handling equipment system, berths, yards and roads.

Simulation supports strategic decision-making in the framework of a CTLOS. In order to obtain a model which can be used as a simulation experiment platform, we develop and apply a model that has universal properties, so that it can be used in different terminal settings. The following key features and assumptions guided the development of the simulation model:

1) The model should be applicable to any ship size and ratio of containers in ships;

2) The model should be applicable to any quay length and number of berths;

3) The berth is allocated dynamically according to quay length and ship size;

4) The model is focused on a QC-ITT-RTG terminal configuration. However, the number of vehicles and cranes and the associated ratios (e.g. the number of ITTs per QC) can be changed. The model should be able to calculate the required amount of and ratio between equipment types;

5) The operational efficiency of the three main equipment types (QC, ITT, and RTG) could follow any probability distribution.

The simulation model is used to provide a comprehensive analysis on equipment utilization rates, operational bottlenecks and sensitivity in order to evaluate and choose a reasonable range of equipment ratios.

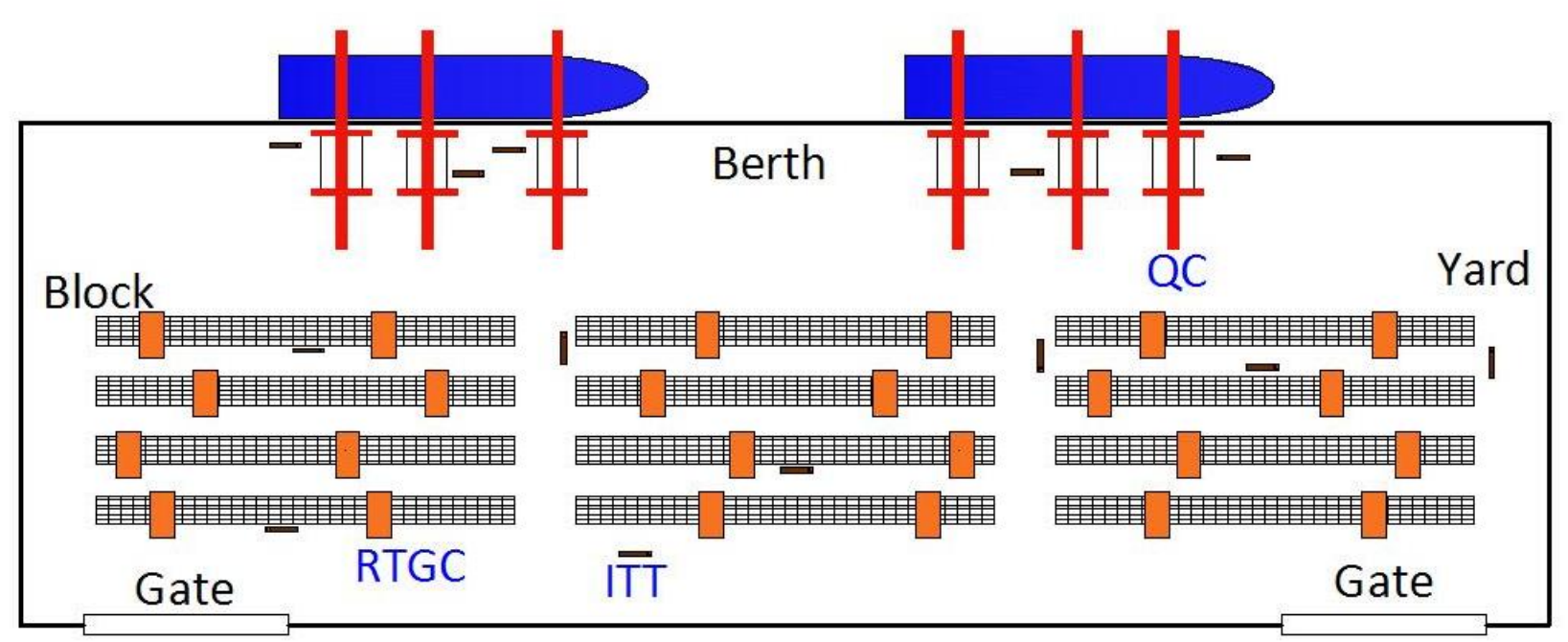

Figure 1. Illustration of CTLOS based on equipment combination GC-RTG-ITT. CTLOS, container terminal logistics operations system; QC, quay cranes; RTG, rubber-tired gantry; ITT, intra-terminal trucks. 
Table 1. Container terminal equipment mix options

\begin{tabular}{|c|c|c|c|}
\hline \multirow[t]{3}{*}{ Container terminal equipment } & Quay equipment & Yard equipment (stacking) & $\begin{array}{l}\text { Intra-terminal (horizontal) } \\
\text { transport equipment }\end{array}$ \\
\hline & \multirow[t]{2}{*}{$\begin{array}{l}\text { Ship-to shore gantry quay } \\
\text { crane - manned (QC) } \\
\text { Ship-to shore gantry quay } \\
\text { crane - remotely operated } \\
\text { (AQC) }\end{array}$} & $\begin{array}{l}\text { Rail mounted gantry crane (RMG) } \\
\text { Rubber tyred gantry crane (RTG) } \\
\text { Unmanned RMG or automated } \\
\text { stacking crane (ASC) } \\
\text { Overhead bridge crane (BC) }\end{array}$ & $\begin{array}{l}\text { Intra-terminal truck or trailer (ITT) } \\
\text { 'Runner' straddle carrier (RSC) } \\
\text { Automated guided vehicles (AGV) }\end{array}$ \\
\hline & & \multicolumn{2}{|c|}{$\begin{array}{c}\text { Straddle carrier }- \text { manned (SC) } \\
\text { Stradde carrier - unmanned (AutoStrad) }\end{array}$} \\
\hline \multicolumn{4}{|l|}{ Real cases on the terminals } \\
\hline $\begin{array}{l}\text { Antwerp Gateway terminal, } \\
\text { Antwerp, Belgium }\end{array}$ & QC & ASC & RSC \\
\hline $\begin{array}{l}\text { Yangshan phase } 4, \\
\text { Shanghai, China } \\
\text { APM T Maasvlakte 2, } \\
\text { Rotterdam, the Netherlands }\end{array}$ & $\mathrm{AQC}$ & ASC & AGV \\
\hline $\begin{array}{l}\text { Pasir Panjang (section drive 1), } \\
\text { Singapore }\end{array}$ & QC & $\mathrm{BC}$ & ITT \\
\hline $\begin{array}{l}\text { Lomé container terminal, } \\
\text { Lomé, Togo }\end{array}$ & QC & RTG & ITT \\
\hline $\begin{array}{l}\text { Dalian container terminal } \\
\text { (DCT), Dalian, China }\end{array}$ & QC & RMG & ITT \\
\hline $\begin{array}{l}\text { MPET Deurganckdock, } \\
\text { Antwerp, Belgium } \\
\text { Jadeweserport, } \\
\text { Wilhelmshaven, Germany }\end{array}$ & QC & & \\
\hline $\begin{array}{l}\text { Patrick's terminal, Brisbane, } \\
\text { Australia }\end{array}$ & QC & & Strad \\
\hline
\end{tabular}

Note: Reach stackers and empty container handlers are not listed in this table as they only serve as main yard equipment in smaller container terminal facilities.

Source: own elaboration by authors.

The equipment utilization rate is the ratio of the total work time of all equipment to the total simulated time of the existing equipment in the simulation system. The range between upper and lower utilization rates cannot be too high or low. High utilization rates decrease the equipment efficiency and increase the vessel service time. Therefore, more equipment should be allocated. Low utilization rates point to an over-allocation of equipment and an underutilization and waste of available terminal assets.

As mentioned earlier, the container terminal operating process simulated in this paper is based on a combination of QCs, ITTs, and RTGs. If the capacity of QCs, ITTs and or RTGs is low, the terminal capacity decreases. Operational bottleneck analysis is used to find the minimum required capacity of QCs, ITTs, and RTGs. QCs are key assets of a terminal as they represent a high operational (OPEX) and capital cost (CAPEX). If ITTs or RTGs form the capacity bottleneck then the number of ITTs or RTGs needs to be increased to match the quayside capacity offered by the QCs. ITTs are the cheapest equipment so removing a bottleneck at ITT level typically is easy and not too expensive or time-consuming. The simulation model allows to observe which equipment type forms the bottleneck during each time interval as well as count the times that QCs, ITTs, and RTGs become the bottleneck within the entire simulation period. Thus, if the bottleneck percentage of QCs exceeds that of RTGs and the latter is higher than the bottleneck percentage of ITT's within the simulation time, then the ratio allocation of QC, ITT, and RTG is reasonable. Moreover, container throughput and berth utilization rates are also important measures that can be used to evaluate the simulation results.

\section{Elements and stochastic variables of the CTLOS simulation model}

CTLOS can be considered as a type of discrete event dynamic system (DEDS). The elements of a DEDS are entity, event, activity and process (EEAP). We apply this EEAP concept to a CTLOS simulation modeling environment, and define the CTLOS as a set of entities, activities, events and processes. 
CTLOS consists of two systems, i.e. the Vessel Berthing and Queuing Operations System and the Terminal Operations System. The latter can be subdivided into four operational processes: (1) the unloading of containers from the ship to vehicles used for intra-terminal transfer; (2) the loading of containers from the intra-terminal transfer vehicles to the ship; (3) Containers received via the gate-in; (4) Containers delivered via the gate-out.

The CTLOS consists of two cycle operations: the "quay-yard" cycle operation is composed of processes 1 and 2; the "in-out gate" cycle operation consists of processes 3 and 4 . Table 2 illustrates the event, activity and process in a CTLOS. In a real-life setting, the system operates in a sequential and concurrent mode simultaneously. We define event, activity and process of the container terminal operation system to approach a real-life system as much as possible (Table 3). Events can be summarized as container movements which drive a series of activities at a simulation interval in each process. A simulation interval is a simulation step with a time value greater than zero and can be set by users of the simulation system. The simulation system advances step by step across the time intervals.

We identified and use three types of stochastic variables for modeling purposes based on a clear understanding of the common characteristics of the different real-life systems.

A first type of stochastic variable is associated with equipment efficiencies, such as the operational efficiencies of QC loading, QC discharging, yard handling equipment, gate processing efficiencies for inbound trucks, and gate processing efficiencies for outbound trucks. The units of these variables are measured in TEU per hour.

A second type of stochastic variable relates to equipment operating time, including ITT travel time and stop time in both the quay-yard cycle and the front-rear yard transfer cycle, and cycle time for yard (re)shuffling. The units of these variables are measured in seconds.

A third type of stochastic variable is vessel-related: (1) the ratio between loaded or discharged volume to the maximum vessel carrying capacity, (2) characteristics of ship types, including maximum TEU capacity, overall ship length and ship clearance, (3) the distribution of different ship types; (4) loading-only ratio, discharging-only ratio, and the ratio of both loading and

Table 2. Event, activity and process of a container terminal operation system

\begin{tabular}{|c|c|c|}
\hline Process & & Event or activity \\
\hline \multirow[t]{7}{*}{ Discharging } & Event & Ship berthed, QC starts, discharging commences \\
\hline & Activity & QC moves, unloading \\
\hline & Event & Discharging completes \\
\hline & Activity & Horizontal transport, cargo transferred from quay to yard \\
\hline & Event & QC movement start \\
\hline & Activity & RTG movement \\
\hline & Event & RTG movement cease \\
\hline \multirow[t]{7}{*}{ Loading } & Event & Ship berthed, ITT ready, RTG moves \\
\hline & Activity & QC moves, containers loaded to ITT \\
\hline & Event & RTG ceases \\
\hline & Activity & Horizontal transport starts, containers moved from yard to quay \\
\hline & Event & Container at quay, crane starts loading \\
\hline & Activity & QC starts moving, containers moved into the ship \\
\hline & Event & Container loaded into the ship \\
\hline \multirow[t]{5}{*}{ In-Gate } & Event & A truck enters the terminal via the in-gate. \\
\hline & Activity & The truck moves from in-gate to the stacking yard. \\
\hline & Event & The truck arrives at the position of stacking yard. RTG starts stacking-up. \\
\hline & Activity & The container is picked up by RTG and stacked up. \\
\hline & Event & RTG finishes stacking-up and stops. \\
\hline \multirow[t]{5}{*}{ Out-gate } & Event & A truck arrives at the stacking yard. RTG starts. \\
\hline & Activity & RTG lowers the container on the truck. \\
\hline & Event & The container is loaded on the truck. RTG stops. \\
\hline & Activity & The truck moves from the stacking yard to out-gate. \\
\hline & Event & The truck leaves the terminal via the out-gate. \\
\hline
\end{tabular}

QC, quay cranes; RTG, rubber-tired gantry; ITT, intra-terminal trucks. 
Table 3. Event, activity and process of CTLOS as defined in the model

\begin{tabular}{|c|c|c|}
\hline Processes & $\begin{array}{l}\text { Events } \\
\text { /activities }\end{array}$ & Explanation \\
\hline $\begin{array}{l}\text { Containers } \\
\text { discharged from ship } \\
\text { through ITT to yard. }\end{array}$ & $\begin{array}{c}\text { Event } \\
\text { Activities }\end{array}$ & $\begin{array}{l}\text { Ship berths; QC starts operations; discharging of containers commences. } \\
\text { Event drives the sequential activities of QC-ITT-RTG which can be divided into the } \\
\text { following activities. } \\
\text { 1) QC moves and unloads container; } \\
\text { 2) ITT transfers container from quay to yard; } \\
\text { 3) RTG moves to appropriate position to pick-up and stack the container. }\end{array}$ \\
\hline $\begin{array}{l}\text { Containers loaded } \\
\text { from RTG through } \\
\text { ITT to ship }\end{array}$ & $\begin{array}{c}\text { Event } \\
\text { Activities }\end{array}$ & $\begin{array}{l}\text { Ship berths; ITT ready in yard; RTG starts to take containers from yard } \\
\text { Event drives the operation-line sequential activities of RTG-ITT-QC which can be divided } \\
\text { into the following activities. } \\
\text { 1) RTG lowers containers onto ITT; } \\
\text { 2) ITT moves containers from yard to quay; } \\
\text { 3) QC moves containers onto the ship. }\end{array}$ \\
\hline $\begin{array}{l}\text { Containers received } \\
\text { via in-gate }\end{array}$ & $\begin{array}{c}\text { Event } \\
\text { Activities }\end{array}$ & $\begin{array}{l}\text { Containers should be received within a certain time frame. } \\
\text { Event drives the operation-line sequential activities at Gate-Yard which can be divided into } \\
\text { the following activities. } \\
\text { 1) The truck moves from in-gate to stacking yard; } \\
\text { 2) The containers are picked up by RTG and stacked. }\end{array}$ \\
\hline $\begin{array}{l}\text { Containers delivered } \\
\text { via out-gate }\end{array}$ & $\begin{array}{c}\text { Event } \\
\text { Activities }\end{array}$ & $\begin{array}{l}\text { Containers should be delivered within a certain time frame. } \\
\text { Event drives the operation-line sequential activities at Gate-Yard which can be divided into } \\
\text { the following activities. } \\
\text { 1) RTGC lowers the container onto the truck; } \\
\text { 2) The truck moves from the stacking yard then through the out-gate. }\end{array}$ \\
\hline
\end{tabular}

CTLOS, container terminal logistics operations system; QC, quay cranes; ITT, intra-terminal trucks; RTG, rubber-tired gantry.

discharging together.

The stochastic parameters can be obtained by the following two approaches: on-site survey and published historical data. The on-site survey method requires statistical analysis and model fitting. For the planning of future ports and in case on-site survey data is not available, the required inputs can be generated based on historical data using stochastic variables.

\section{Layers in the CTLOS simulation model}

We approach container terminal operations from different abstract layers in view of building a multi-layered simulation model. First, we build a simulation model which consists of three sub-models. The events, activities and processes of Table 3 are encapsulated in the corresponding simulation sub-systems. The information and data can be invoked among simulation subsystems in accordance with the intervals of the simulation time which is consistent across each sub-simulation.

The CTLOS simulation includes three sub-systems: 1) Vessel berthing and queuing simulation sub-system based on the vessel berthing and queuing sub-model; 2) Loading-discharging simulation sub-system based on the loading-discharging submodel; 3) Yard-gate simulation sub-system based on the yard-gate sub-model. The loading-discharging system is the most important sub-system as it describes the most significant part of the terminal operations.

Simulation can be driven by either event or time. This paper uses a kind of time-driven simulation, i.e. all system-state transitions are synchronized by the simulation clock. " $\mathrm{t}$ " is used to indicate a time-step. Figure 2 represents the simulation model and the relationships among the three sub-models.

\subsection{Vessel berthing and queuing sub-model}

Figure 3 shows the Vessel Berthing and Queuing (VBQ) sub-model. A future event table can be created after running this model. The event table provides information on ship arrival numbers and sequence, along with ship characteristics and the vessels' loading-discharging mode (which can be invoked by the other two simulation sub-systems). 


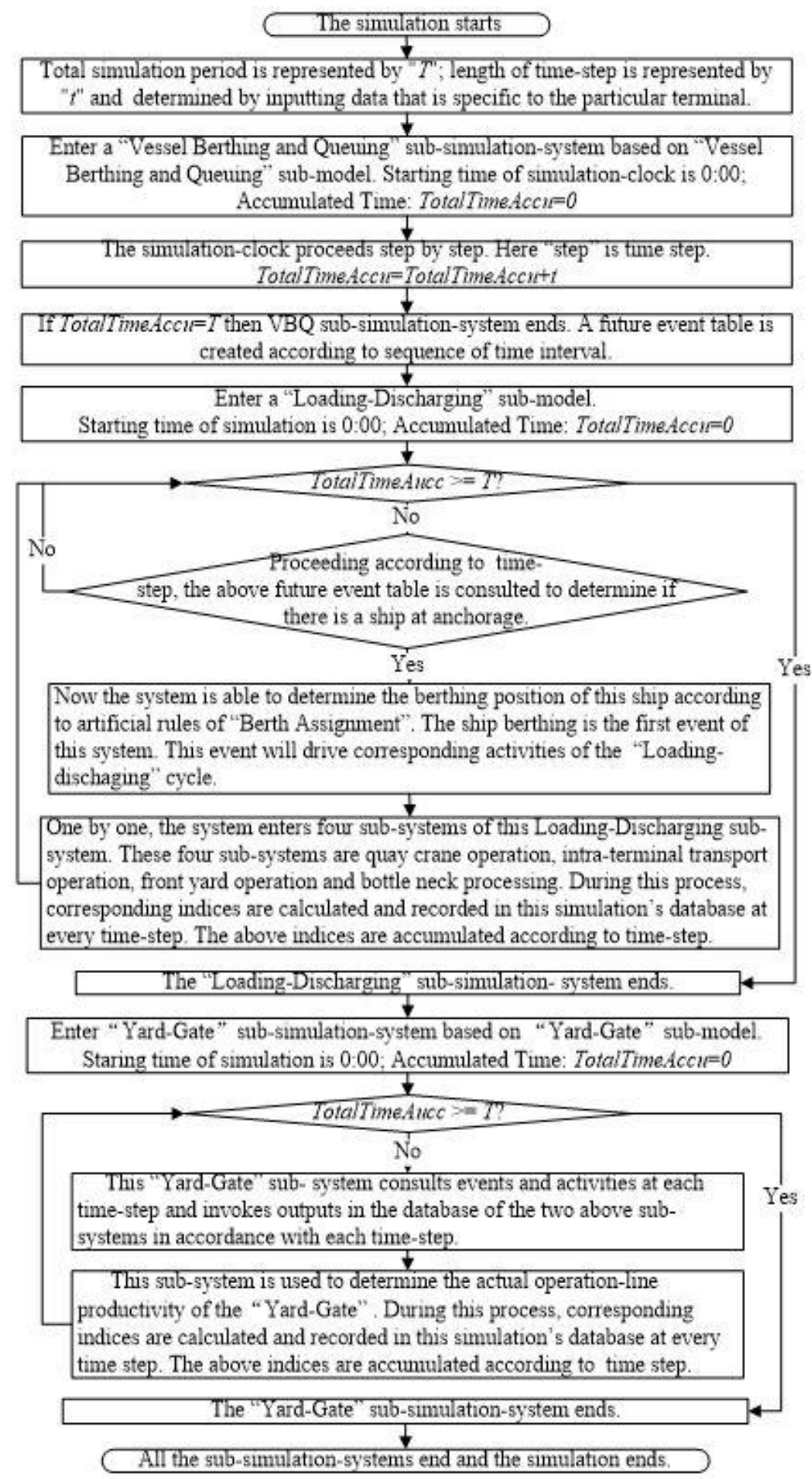

Figure 2. Top-level modeling and relationships among the three sub-models.

\subsection{Loading-discharging sub-model}

The loading-discharging sub-model is the most important of the three simulation sub-models. It combines several operational problems such as dynamic berth assignment, QC assignment, QC operation, ITT operation, yard operation, and bottleneck assessment. Figure 4 presents the overall sub-model of loading-unloading operations.

The rules used in the "loading-discharging" sub-model are as follows: 


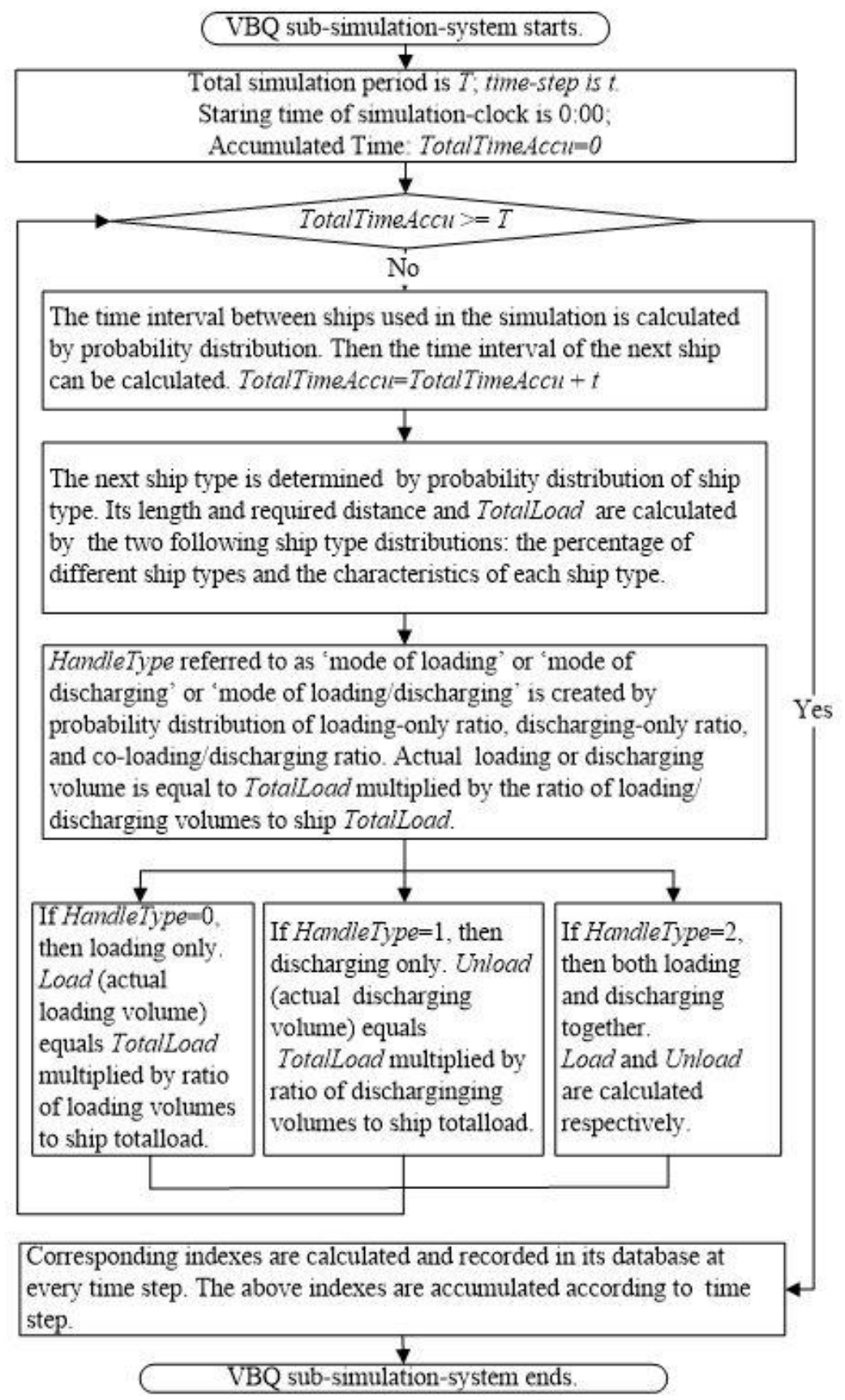

Figure 3. VBQ sub-model.

\subsubsection{Dynamic berth assignment}

This model deals with the dynamic berth assignment problem by using the following rules. When a ship arrives, it queues at anchorage. When a berth becomes vacant, it leaves the anchorage and proceeds to the berth. A berth becomes idle/available when the berth length at a certain time is equal or larger than the combined length of the ship's length and the required separation distance between ships.

\subsubsection{Quay-crane assignment}

This model assigns QCs to the terminal's berths. The number of cranes allocated to each berth at every simulation time step is determined by a trade-off between the number of cranes required by ship type and the available number of cranes at the 


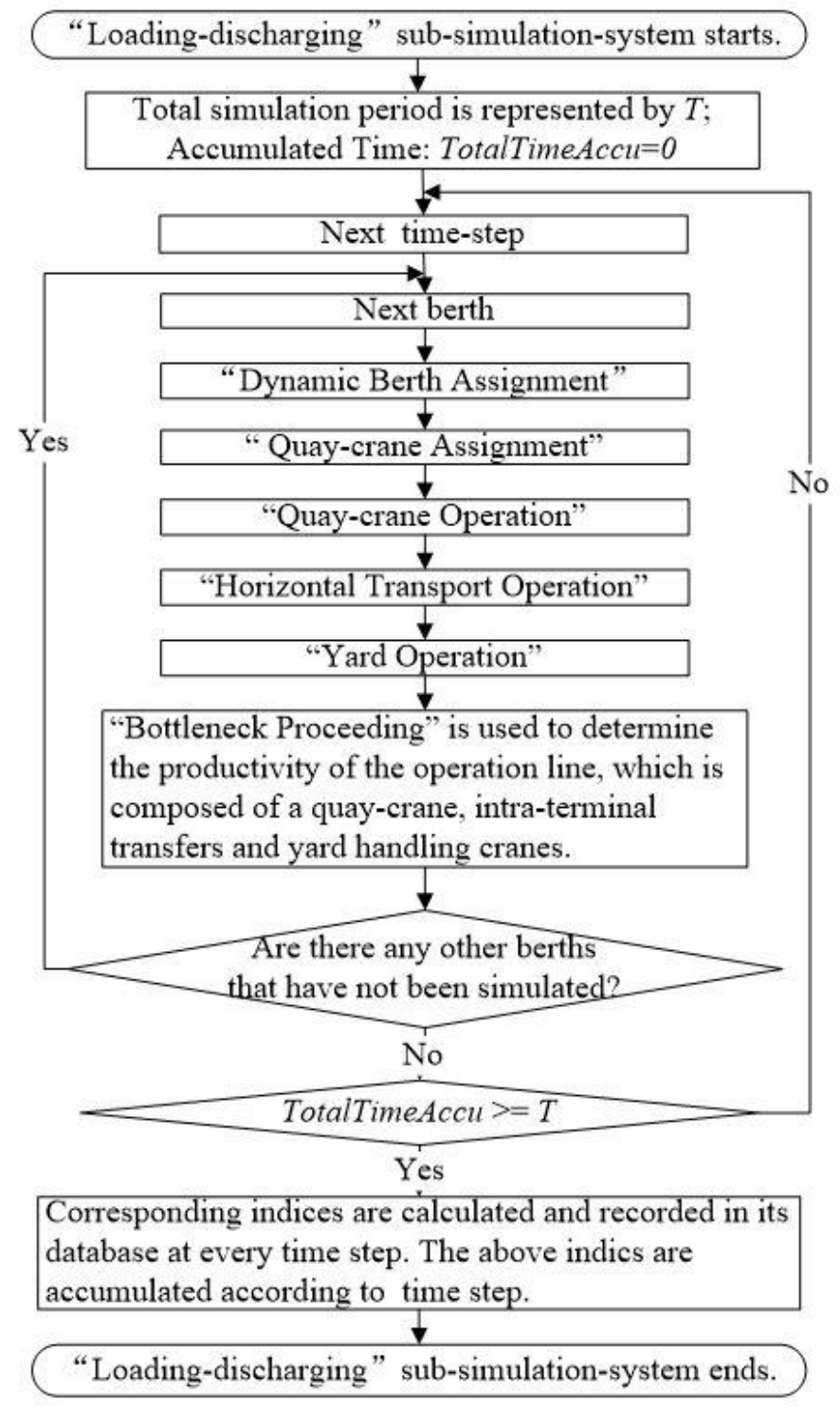

Figure 4. Overall sub-model of loading-unloading operations.

container terminal. The model determines how the cranes will be allocated in case the total number of cranes required to load or unload all the ships exceeds the number of cranes available at the terminal. The minimum number of cranes required to load or unload is determined in the following manner: the largest ship gets the first consideration and the next largest ship gets the second consideration and so on to the smallest ship. The applied QC assignment rules are used to run the simulation model but can be changed if required. For example, existing operational agreements between a terminal operator and a shipping line might specify a minimum guaranteed number of gantry cranes in case the ship arrives within specified time windows (also called the required crane density). In such a case, the QC assignment will have to consider the vessel priority and crane density rules contained in the agreements (see also Iris et al., 2018).

\subsubsection{QC operation}

This sub-model reflects the quay-crane productivity. The duration of the cycle is calculated as follows:

$$
\operatorname{CTcr}_{\text {load }}=t_{1, \text { load }}-t_{0, \text { load }}
$$

in which $t_{0, \text { load }}$ denotes the time when the QC starts handling a container and $t_{l, \text { load }}$ denotes the time when the QC completes 
the handling and the next handling starts. Similarly, the unloading cycle is determined by:

$$
\text { CTcr }_{\text {unload }}=t_{1, \text { unload }}-t_{0, \text { unload }}
$$

The efficiency of the QC is calculated as follows. $P Z_{\text {load }}$ is the loading efficiency of the QC:

$$
P z_{\text {load }}=\frac{3,600}{C T c r_{\text {load }}}\left(2-R_{1}\right)
$$

$P Z_{\text {unload }}$ is the unloading efficiency of the QC:

$$
P z_{\text {unload }}=\frac{3,600}{C T c r_{\text {unload }}}\left(2-R_{1}\right)
$$

where $R_{I}$ is the percentage of TEUs (twenty foot containers) to that of the sum of TEUs and FEUs (forty foot container).

\subsubsection{ITT operation}

A meaningful simulation must factor in equipment downtime. There are several key factors contributing to equipment downtime: the poor interface between equipment, the poor efficiency of some equipment, an inappropriate equipment ratio, and sub-optimal operational scheduling.

Congestion might be found at the terminal in two different cycle-operations: (a) Loading and discharging operations from the QC to the yard or vice versa, and (b) container transfer from the front yard to the rear yard or vice versa.

In an actual container yard, traffic moves on either one- or two-lane roads. Congestion occurs when there is a speed difference between ITTs traveling in the same direction (for example, when a vehicle is stuck behind another vehicle that must proceed slowly for whatever reason) or when a vehicle is blocked by other equipment. The former type of congestion is referred to as traveling congestion and can be expressed using the following equation:

$$
\frac{S_{a}}{V_{i}-V_{j}}<\frac{L}{V_{j}}
$$

where $S_{a}$ is the distance between equipment $i$ and equipment $j, V_{i}$ is the traveling speed of equipment $i$, and $V_{j}$ is the traveling speed of equipment $j$.

The latter type of congestion is referred to as blocking congestion. If transfer equipment $T r_{i}$ is handling containers (e.g. pickups) in a single-lane, other transfer equipment $T r_{j}$ may have to stop and wait. Blocking congestion will occur when

$$
\frac{S_{c}}{V_{j}}+t_{j}>t_{j}+t_{\text {stay }}
$$

where $S_{c}$ is the distance between equipment $i$ and $j, t_{\text {stay }}$ is the amount of time spent waiting.

To deal with the issue of yard congestion in the simulation, we introduce the notion of abnormal stoppage time that can be used regardless of the type of congestion. The abnormal stop time of an ITT/trailer is obtained by a prescribed statistical distribution.

After the abnormal stop time is presented, the ITT cycle time is defined as the time completed by ITT from the berth to the stacking yard and from the stacking yard back to the berth. This is mathematically presented as:

$T_{\text {vehicle }}=T_{\text {run }}+T_{\text {berth }}+T_{\text {site }}+T_{\text {abnom }}$

where $T_{\text {vehicle }}$ is the total cycle time, $T_{\text {run }}$ is the non-stop traveling time of the cycle, $T_{\text {berth }}$ is the waiting time at berth, $T_{\text {site }}$ is the waiting time at yard, and $T_{\text {abnom }}$ is the abnormal waiting time in a cycle due to congestion or operations.

ITT will generate a certain quantity within a time step, which can be expressed as: 


$$
\begin{aligned}
& V_{t r}=P_{t r} t(\text { LineMachine }), \\
& P_{t r}=\frac{3,600}{T_{\text {vehicle }}} V_{\text {tr }} r_{\text {cycle }}, \\
& T_{\text {vehicle }}=T_{\text {run }}+T_{\text {berth }}+T_{\text {site }}+T_{\text {abnom }}
\end{aligned}
$$

where $V_{t r}$ denotes the number of containers handled by ITT, $P_{t r}$ denotes the efficiency of ITT, LineMachine denotes the number of trucks required per QC, and $V t r_{\text {cycle }}$ denotes the average number of containers that the equipment carries.

\subsubsection{Yard operations}

The QC handling capacities can be defined in terms of total TEU handled per hour. This will generate a certain quantity within a time step, which can be expressed as

$$
V_{c r}=P_{c r} t(\text { LineYardCrane })
$$

where $P_{c r}$ denotes the efficiency of a QC, LineYardCrane denotes the number of RTGs required per QC, and $V t_{c y c l e}$ denotes the number of containers that the yard cranes deal with at a certain time step.

\subsubsection{Productivity of the cycle based on bottleneck analysis}

This model calculates the actual productivity of a QC and the corresponding ITTs and RTGs within the period of each simulation time step and the total simulation time.

For the loading-discharging cycle, the minimum volume is the smallest volume among the volumes produced by the QCs, ITTs or RTGs respectively. This minimum volume corresponds to the actual productivity of the entire cycle. During this process, corresponding indices are calculated at each step and recorded in the simulation's database.

\subsection{Yard-gate sub-model}

The yard-gate sub-model calculates the number of containers that should be received and delivered at each time step in the VBQ sub-model and the loading-discharging sub-model. For each time step, the system compares this number with the carrying capacity of the yard cranes in order to determine the minimum number of containers that can be carried, thus determining the actual productivity of the yard-gate cycle. During this process, corresponding indices are calculated and recorded in the simulation's database at every time step. The above indices are accumulated per time step.

\subsection{Simulation system configuration}

The above simulation sub-models were used as building blocks of a logistics simulation system for a generic container terminal. The framework of this simulation system is shown in Figure 5. The interfaces developed for the simulation system and the actual running of the simulation are shown in Figures 6 and 7. The numerical simulation forms the core of the simulation system and its sub-models. The results of the computations are recorded in the system's database.

Given the model set-up, the simulation system can be used for different terminals set-ups. For planning purposes, the simulation system can be fed with data obtained from existing terminals to solve the equipment ratio problem in newly established, extended or upgraded container terminals. In the next sections, we present an empirical application of the simulation system using data from container terminals in Shanghai.

\section{Simulation experiment}

\subsection{Case description and data collection}

Since the start of China's opening up policy, the Chinese container port system has witnessed a fast growth path (Notteboom and Yang 2017). In 2003, the container throughput of Chinese ports surpassed the volumes handled by any other national port 


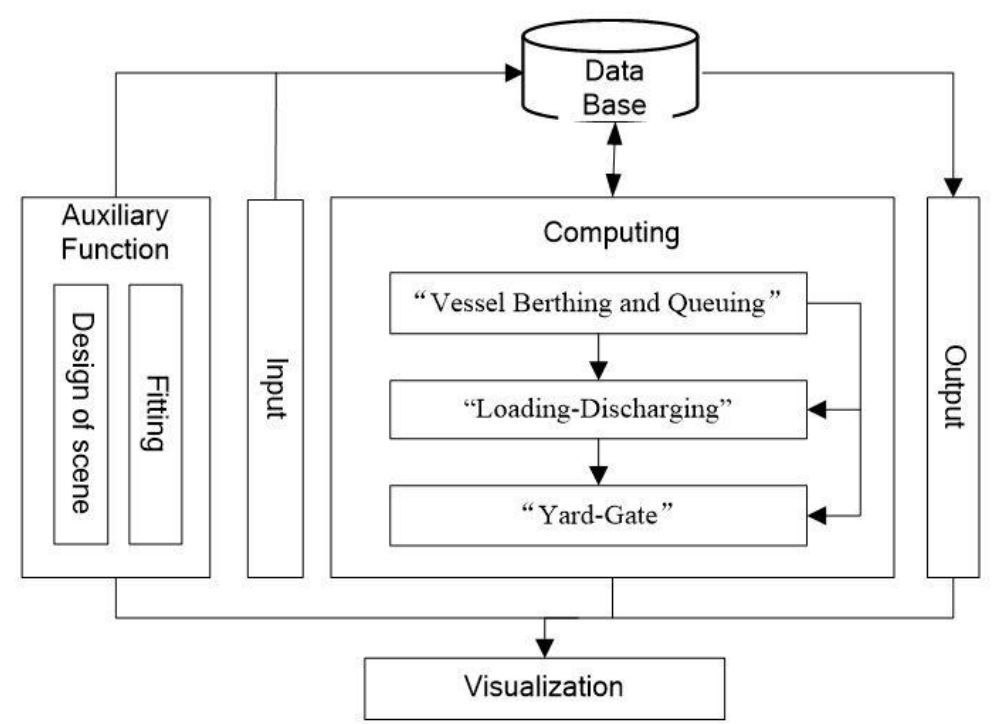

Figure 5. The simulation system framework.

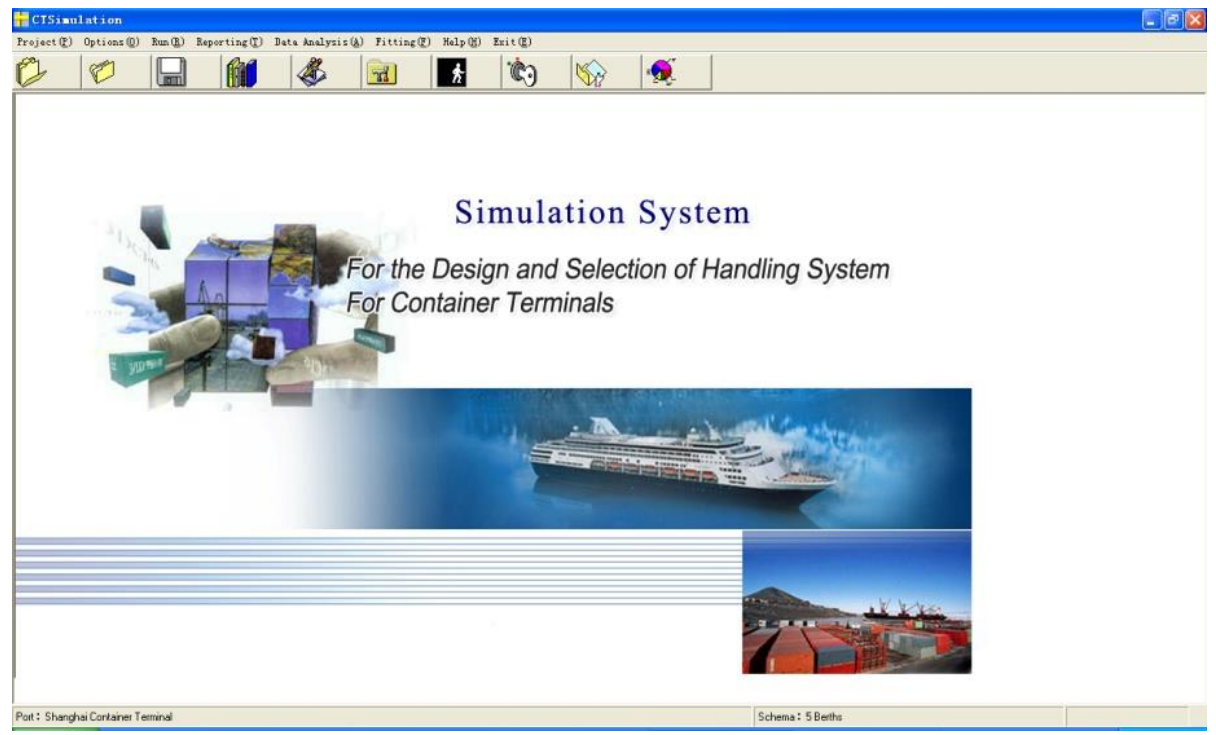

Figure 6. Interface of the simulation system.

system in the world. In 2019, six out of the world's ten largest container ports were found in China with Shanghai positioned as the world's largest container port with a container throughput of 43.3 million TEU. Since the mid-1990s, the steep rise of container demand in Shanghai was accommodated by a series of new terminals in the Waigaoqiao area at the south bank of the Yangtze estuary. Phases IV and V of the Waigaoqiao development involved the opening of the Shanghai East Container terminal (SECT) in 2002 and the Shanghai Mingdong Container Terminal (SMCT) in 2005. Terminal capacity and nautical conditions at the terminals along the Yangtze river were no longer sufficient to accommodate future growth. Therefore, Yangshan, a group of small islands located at the mouth of Hangzhou Bay, was chosen as the location for a new massive offshore terminal complex connected to the mainland via the newly constructed Donghai road bridge with a length of $31.5 \mathrm{~km}$. The first phase of the Yangshan complex was opened in 2005. Phase 4 was completed in 2017 and involves a fully automated terminal using a combination of AQC (automated quay crane), AGV (automated guided vehicles) and ASC (automated stacking crane) (Table 1). All other terminals in Shanghai are based on the QC-ITT-RTG or QC-ITT-RMG equipment configuration.

In this section, we apply the simulation system to simulate container terminal operations at Phase I of the Shanghai Yangshan Deep Water Port by partly using basic data from phase IV of Shanghai Waigaoqiao container terminal in 2004 and vessel data at Yangshan port from 2004 to 2014. 


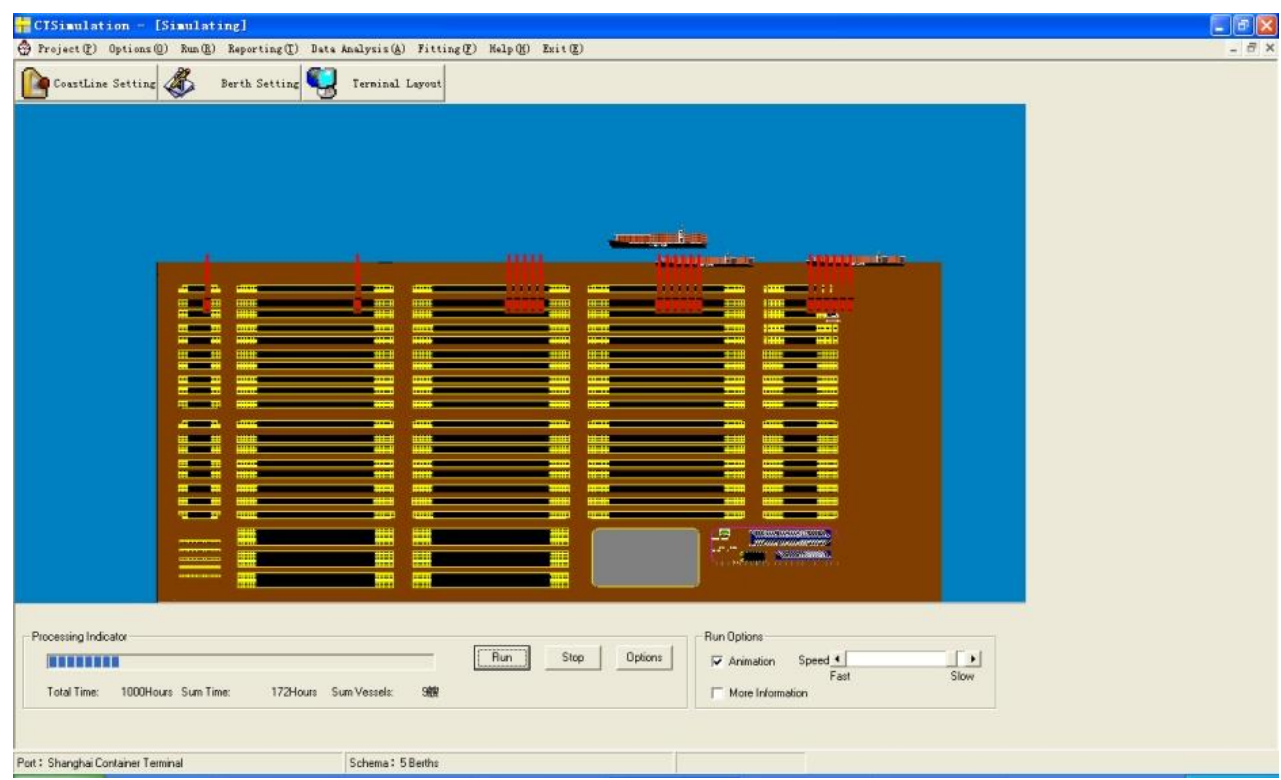

Figure 7. Interface to visually show the simulation running.

Two methods are widely used to obtain operational data for container terminals: 1) the use of actual data of other terminals; 2) forecasts for the studied terminal in combination with data of other existing ports. The data on random variables used in the case study was obtained through on-site measurements at phase IV of Shanghai Waigaoqiao container terminal in 2004 and original data of the container terminal database. The probability distributions and empirical data were checked for suitability and validity before being used in the simulation system. For example, the skills of the crane drivers are similar in the same region. We used actual data of phase I of Yangshan port for determining the loading and discharging efficiency of QCs and yard equipment. We used forecasts for Yangshan in combination with data of phase IV of Waigaoqiao container terminal to obtain the ITT cycle time because the size and layout of the two terminals is similar.

For the discharging efficiency of yard cranes, we fitted data of the discharging cycle time. We recorded on-the-spot sample data (unit is seconds) for 72 hours. We found that 50 seconds is the time interval, and 25.01 is the starting point. Through fitting and testing, we found that the discharging cycle time follows an exponential distribution. The value of parameter $\mu$ is 43.2. The discharging efficiency was obtained by dividing the discharging cycle time by 3,600 (the unit of measurement is containers per hour).

The loading efficiency of yard cranes was obtained by fitting data on the loading cycle time. We recorded on-the-spot sample data (the unit of measurement is seconds) for 72 hours and also in this case 50 seconds is the time interval with 25.01 as the starting point. Through fitting and testing, we found that the discharging cycle time follows a normal distribution. The value of parameter $\mu$ is 23.5 ando19.4. To obtain the loading efficiency, we divided the loading cycle time by 3,600 (unit is containers per hour).

The ITT transport cycle time was calculated through fitting the relationship of time and distance. We used Matlab to fit onspot sample data we collected from the container terminal. The following function was found:

$$
\mathrm{y}=0.73 x^{2}-1.2 x+5.7
$$

where $x$ is distance in kilometer and y is time expressed in hundreds of seconds. The distance range is from 0 to 3.067. The time range is from 0.592 to 8.667 . Figure 8 shows the data fitting process using Matlab.

\subsection{Definition of the research boundary in the simulation experiment}

The conditions before simulation are as follows. The berth length is 1,600 meters in 2005 when Phase I of the Shanghai Yangshan Deep Water Port started operations. The number of berths is calculated following a dynamic approach. The operational system of QC-ITT-RTG is adopted. The stacking yard of Yangshan Deep Water Port is designed considering actual container demand. We assume that the rate of container shifts is 0 . As we are applying the simulation system to support strategic 


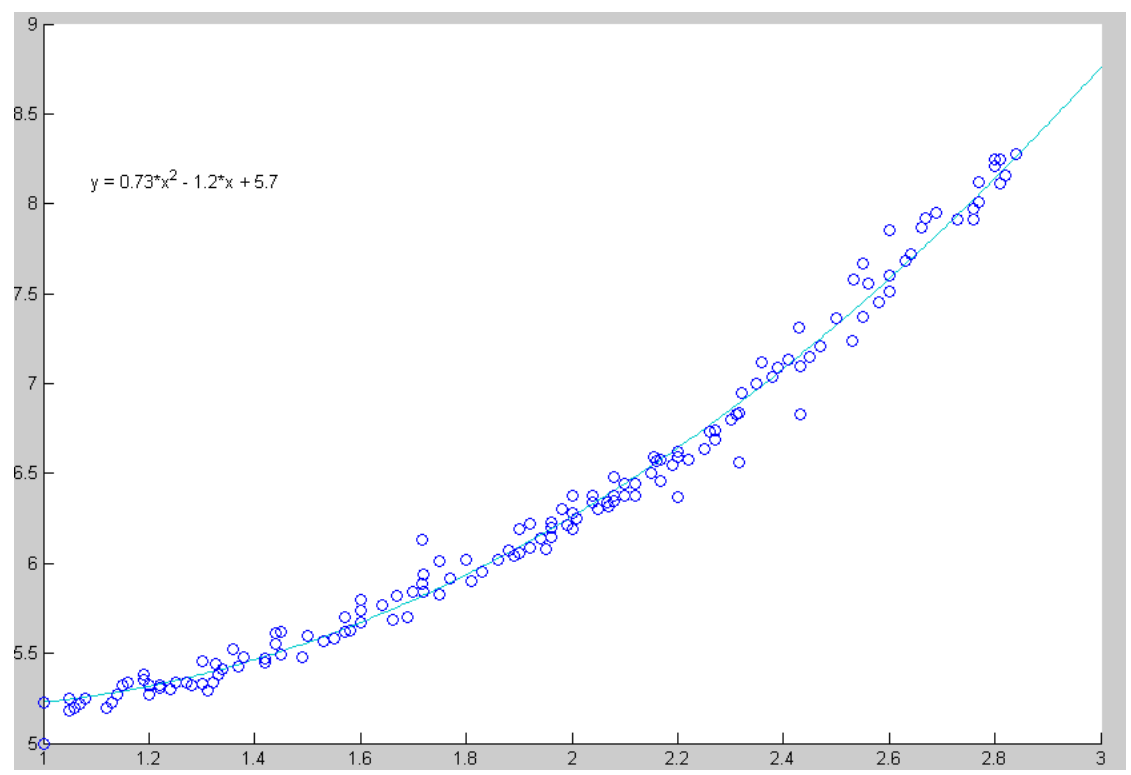

Figure 8. Data fitting using Matlab.

decisions at the level of terminal layout and equipment, the simulation time is rather long and set at 8,400 hours to cover the operational days in one year. The time step is set at 2 hours.

\subsection{Formation of solution clusters}

The experiment framework of equipment matching proportions is as follows: 10-25 QCs; each QC is equipped with 2, 3, 4, and 5 ITTs, and 1.5, 1.8, 2.1, 2.4, 2.7, 3, 3.2, 3.5, and 4 RTGs respectively. First, we repeatedly adjusted the experiment framework, ran the simulations and inputted the results. Second, we identified the pivot parameters influencing the empirical case. Finally, we adjusted the parameters and formed program groups through which we obtained the optimal equipment ratios.

\subsection{Determination of the core program}

We compared the simulation results of the program groups and determined the core program with bottleneck analysis and machine utilization rate analysis, i.e., 14-19 QCs; each QC equipped with 4 and 5 ITTs, and 2.1, 2.4, 2.7, and 3 RTGs.

\subsection{Adjusting parameters and analyzing throughput, utilization rates, bottlenecks and sensitivity impacts on core program}

Next, we adjusted the parameters and measured different programs with a central focus on the core program and the practical feasibility. For instance, we adjusted the parameters to anticipate a higher vessel arrival density and a higher number of largecapacity vessels in line with the trend towards scale increases in container vessel size. Before the parameter adjustment, the annual throughput reached 2.39-2.85 million TEU and the berth utilization rate amounted to 43\%-60\% with an average berth utilization rate of 50\%. After adjustments, the annual throughput increased to 2.90-3.35 million TEU and the berth utilization rate reached $48 \%-68 \%$ with an average berth utilization rate of $62 \%$.

\subsection{Results of the simulation experiment}

The simulation exercise led to the following outcomes:

(1) Analysis of equipment utilization rates. The blue-colored data in Table 4 relate to an average equipment utilization rate (AUR) that is either too high or too low. Therefore, the simulation does not provide reasonable results. The yellow-colored cells in the table point to utilization rates for RTGs that are lower than in the case of ITTs. Also here, the simulation results are not reasonable. We find that the most reasonable program is to have 16 to 18 QCs with 5 ITTs per QC (i.e. the orangecolored cells), leading to similar but rather low AURs for both ITTs and RTGs (AUR does not exceed 50\%). 
Table 4. AUR of terminal equipment (the ratio of QC to RTG is 1 to 2.4)

\begin{tabular}{|c|c|c|c|c|c|c|c|c|c|}
\hline \multirow{3}{*}{$\begin{array}{c}\text { Number } \\
\text { of QC }\end{array}$} & \multicolumn{9}{|c|}{ Ratio of QC to ITT } \\
\hline & \multicolumn{3}{|c|}{$1: 4$} & \multicolumn{3}{|c|}{$1: 4.5$} & \multicolumn{3}{|c|}{$1: 5$} \\
\hline & $\begin{array}{c}\text { AUR of QC } \\
(\%)\end{array}$ & $\begin{array}{c}\text { AUR of ITT } \\
(\%)\end{array}$ & $\begin{array}{c}\text { AUR of RTG } \\
(\%)\end{array}$ & $\begin{array}{c}\text { AUR of QC } \\
(\%)\end{array}$ & $\begin{array}{c}\text { AUR of ITT } \\
(\%)\end{array}$ & $\begin{array}{c}\text { AUR of RTG } \\
(\%)\end{array}$ & $\begin{array}{c}\text { AUR of QC } \\
(\%)\end{array}$ & $\begin{array}{c}\text { AUR of ITT } \\
(\%)\end{array}$ & $\begin{array}{c}\text { AUR of RTG } \\
(\%)\end{array}$ \\
\hline 14 & $>90$ & $>90$ & $75-80$ & $85-90$ & $65-70$ & $65-70$ & $>90$ & $60-65$ & $70-75$ \\
\hline 15 & $85-90$ & $60-65$ & $70-75$ & $85-90$ & $65-70$ & $60-65$ & $85-90$ & $55-65$ & $55-65$ \\
\hline 16 & $80-85$ & $60-65$ & $50-55$ & $80-85$ & $60-65$ & $50-55$ & $80-85$ & $50-55$ & $50-55$ \\
\hline 17 & $75-80$ & $60-65$ & $50-55$ & $65-70$ & $50-55$ & $45-50$ & $70-75$ & $45-50$ & $45-50$ \\
\hline 18 & $60-65$ & $50-55$ & $40-45$ & $65-70$ & $50-55$ & $45-50$ & $65-75$ & $40-50$ & $45-50$ \\
\hline 19 & $60-65$ & $50-55$ & $35-40$ & $60-65$ & $45-50$ & $35-40$ & $60-65$ & $40-45$ & $35-40$ \\
\hline
\end{tabular}

AUR, average equipment utilization rate; QC, quay cranes; RTG, rubber-tired gantry; ITT, intra-terminal trucks.

(2) Bottleneck analysis. Taking into account the discussion on bottlenecks in section 3, the possibility of having bottlenecks at QC level should be minimized, as bottlenecks at RTGs and particularly at ITT level can be solved in a cheaper and less intrusive way. The simulation results show that if we have 16 to $18 \mathrm{QCs}$, the reasonable proportion of QC to RTGs is 2.1-2.4. The number of ITTs becomes too low when the proportion of ITTs per QC goes below 4.5.

(3) When we adjust the parameters and increase the container throughput by $10 \%-30 \%$, the reasonable proportion of QC to ITTs is $1: 5$ to $1: 6.3$ and the reasonable proportion of QC to RTGs is $1: 2.6$ to $1: 2.8$.

\subsection{Discussion and validation}

The simulation generates the following final solution: (1) 16 to 18 QCs; (2) 5 ITTs per QC; (3) 2.6 to 2.8 RTGs per QC. When the number of QCs falls below the reasonable range, the mentioned equipment ratios are not effective. When the annual throughput amounts to 2.39-2.85 million TEU and the number of QCs equals 16 to 18, the average utilization rate of the QCs is $55 \%-65 \%$. When the annual throughput amounts to $2.90-3.35$ million TEU and the number of QCs is 16,17 , or 18 , then the average utilization rate of QCs reaches $80 \%-85 \%, 70 \%-75 \%$ or $65 \%-75 \%$ respectively. If the annual throughput increases with 30\%, the reasonable proportion of QCs to ITT becomes 1:6 and the reasonable proportion of QCs to RTGs amounts to $1: 2.8$.

For validation purposes, we compare the modelling results to the actual situation at Yangshan deep water port in Shanghai. The real equipment ratios for Yangshan deep water port in 2006 were 18 QCs, 90 ITTs and 45 RTGs, pointing to a QC/ITT ratio of 1:5 and a QC/RTG ratio of 1:2.5. The real annual throughout amounted to 3.2 million TEU in 2006 (note that the terminal started operations in November 2005). These figures are in line with the model output which pointed at 5 ITTs per QC and 2.6 to 2.8 RTGs per QC.

In the meantime, the length of the terminal has been extended from 1,600 $\mathrm{m}$ to 3,000 $\mathrm{m}$ and the number of QCs has been increased to 34. Table 5 shows the ratios of QC to ITTs and QC to RTGs from 2011 to 2015 at Yangshan deep water port. The figures from 2011 to 2015 point to an ITT to QC ratio of 5.9-6.1 and an RTG to QC ratio of 2.8-2.9. These figures correspond

Table 5. Ratios of ITTs to QC and RTGs to QC from 2011 to 2015

\begin{tabular}{cccccc}
\hline Year & $\begin{array}{c}\text { Number } \\
\text { of QCs }\end{array}$ & $\begin{array}{c}\text { Ratio of ITTs } \\
\text { to QC }\end{array}$ & $\begin{array}{c}\text { Ratio of RTGs } \\
\text { to QC }\end{array}$ & $\begin{array}{c}\text { Throughput } \\
\text { (TEU) }\end{array}$ & $\begin{array}{c}\text { Increase rate in } \\
\text { throughput }(\%)\end{array}$ \\
2006 & 18 & 5 & 2.5 & $3,236,000$ & --- \\
2011 & 34 & 5.9 & 2.9 & $7,133,342$ & 18 \\
2012 & 34 & 6.0 & 2.9 & $7,550,083$ & 18 \\
2013 & 34 & 6.2 & 2.9 & $7,611,423$ & 24 \\
2014 & 34 & 6.2 & 2.8 & $8,100,018$ & 25 \\
\hline
\end{tabular}

Note: We assume the basic throughput is equal to: 3,236,000 $\times(3,000 / 1,600)=6,067,500$ TEU. The increase in throughput in 2011 is: $(7,133,342-6,067,500) / 6,067,500=18 \%$. ITT, intra-terminal trucks; QC, quay cranes; RTG, rubber-tired gantry. 
well to our model output for the case of an annual throughput increase with 30\%, giving an ITT to QC ratio of 6 and an RTG to QC of 2.8. The high similarity between the simulation output and the real data shows that the simulation system is effective in generating realistic results.

\section{Conclusions}

The equipment mix and the ratios between quay, yard and intra-terminal transfer equipment in a CTLOS are key aspects in terminal design and operations. This paper presented a generic simulation model to simulate and finally determine the equipment allocation within an integrated handling system. In particular, we focused on the determination of the optimal ratios between QCs, rubber-tired gantries (RTG) and intra-terminal trucks (ITT). First, we formulated the four basic elements (i.e., EEAP) to lay the foundation for the simulation model and identified the stochastic variables in the system. Second, we created a generic simulation model for the CTLOS consisting of three sub-models: ship queue, loading-unloading operations and yardgate operations. Finally, the simulation model was empirically applied to phase 1 of the Shanghai Yangshan Deep Water Port. The model outputs were compared to the actual situation at phase 1 of the Yangshan terminal complex.

The findings are as follows. First, we found that the unloading operations of QCs and the cycle time follow an exponential distribution and normal distribution respectively. The average loading efficiency turned out to be different from the average unloading efficiency. By integrating time and distance in the horizontal container handling movements, we solved the problem of deducing the horizontal movement cycle for different terminal sizes and layouts.

Second, we found that, in the case of Yangshan phase 1, the reasonable range of the QC-ITT ratio is 1:5 to 1:6.3 and the reasonable range of the QC-RTG ratio is 1:2.4 to 1:2.8. The final determination of these ratios depends on the terminal's container throughput, the equipment utilization rates and the bottleneck probabilities for QCs, ITTs, and RTGs. When the number of QCs is beyond the reasonable range, the equipment ratios mentioned earlier are no longer effective.

This paper contributes to extant literature in a number of ways and also has relevance to practitioners in the terminal operations field. First, the study combines quay and yard-related scheduling problems, thereby extending the traditional BAP, QCAP, and YAP assignment problems, which each focus on one specific part of a CTLOS. Contrary to other integrated terminal optimization analyses, we presented a method to determine the optimal equipment ratios. The choices made at the level of these ratios strongly shape integrated berth and yard scheduling problems associated with the chosen equipment mix.

Second, we conducted numerical experiments based on realistic terminal settings. The presented simulation system can use data of existing terminals to solve the ratio problem in the planning phase of new, extended or upgraded container terminals. The results indicate that the simulation output matches with the real data, thereby underlining the validity and practical usefulness of the model. The simulation model and system can be transplanted to other terminals to support strategic decisions on the ratios between quay, yard and intra-terminal equipment in an integrated handling system, and to obtain an optimal equipment mix.

Third, CTLOS is a DEDS characterized by randomness, complexity and dynamism. We have demonstrated from a methodology point of view that it is feasible to construct a generic simulation model which can deal with any ship size, any container mix in the ship, any quay length and number of berths. The berth is allocated dynamically according to quay length and ship size. While we focused on a QC-ITT-RTG terminal setup, the simulation model can be applied to different equipment types and ratios. Furthermore, the efficiency of the quay, yard and intra-terminal equipment can be in accordance with any probability distribution.

Finally, the paper provides insight on how different operational settings can affect the optimal equipment mix and ratios. More in particular, a comprehensive analysis of container throughputs, equipment utilization rates, and operational bottlenecks, as well as a sensitivity analysis made it possible to evaluate and choose reasonable ratio ranges between the main equipment types in a container handling system under different circumstances. These results have practical relevance and managerial implications in case decisions need to be made about the number and assignment of different types of terminal equipment.

\section{Acknowledgements}

This work was sponsored by National Natural Science Foundation Project (NSFC General Projects in Management \#71172076) in China.

\section{References}

Abou Kasm, O., Diabat, A. Cheng, T. C. E., 2020. The integrated berth allocation, quay crane assignment and scheduling 
problem: Mathematical formulations and a case study. Annals of Operations Research 291, 435-461.

Agra, A., Oliveira, M., 2018. MIP approaches for the integrated berth allocation and quay crane assignment and scheduling problem. European Journal of Operational Research 264, 138-148.

Assadipour, G., Ke, G. Y., Verma, M., 2014. An analytical framework for integrated maritime terminal scheduling problems with time windows. Expert Systems with Applications 41, 7415-7424.

Azab, A., Karam, A., Eltawil, A., 2020. A simulation-based optimization approach for external trucks appointment scheduling in container terminals. International Journal of Modelling and Simulation 40, 321-338.

Bernhofen, D. M., El-Sahli, Z., Kneller R., 2016. Estimating the effects of the container revolution on world trade. Journal of International Economics 98, 36-50.

Cao, J. X., Lee, D. H., Chen, J. H., Shi, Q. X., 2010. The integrated yard truck and yard crane scheduling problem: Benders' decomposition-based methods. Transportation Research Part E: Logistics and Transportation Review 46, 344-353.

Chen, G., Govindan, K., Golias, M. M., 2013. Reducing truck emissions at container terminals in a low carbon economy: Proposal of a queueing-based biobjective model for optimizing truck arrival pattern. Transportation Research Part E: Logistics and Transportation Review 55, 3-22.

Chen, L., Bostel, N., Dejax, P., Cai, J., Xi, L., 2007. A tabu search algorithm for the integrated scheduling problem of container handling systems in a maritime terminal. European Journal of Operational Research 181, 40-58.

Chen, L., Lu, Z., 2012. The storage location assignment problem for outbound containers in a maritime terminal. International Journal of Production Economics 135, 73-80.

Cho, S. W., Park, H. J., Lee, C., 2020. An integrated method for berth allocation and quay crane assignment to allow for reassignment of vessels to other terminals. Maritime Economics \& Logistics. https://doi.org/10.1057/s41278-020-00173-4

Dragović, B., Tzannatos, E., Park, N. K., 2017. Simulation modelling in ports and container terminals: Literature overview and analysis by research field, application area and tool. Flexible Services and Manufacturing Journal 29, 4-34.

Fransoo, J. C., Lee C. Y., 2013. The critical role of ocean container transport in global supply chain performance. Production and Operations Management 22, 253-268.

Ge, J., Zhu, M., Sha, M., Notteboom, T., Shi, W., Wang, X., 2019. Towards 25,000 TEU vessels? A comparative economic analysis of ultra-large containership sizes under different market and operational conditions. Maritime Economics \& Logistics. Available at: https://doi.org/10.1057/s41278-019-00136-4

He, J., Huang, Y., Yan, W., Wang, S., 2015. Integrated internal truck, yard crane and quay crane scheduling in a container terminal considering energy consumption. Expert Systems with Applications 42, 2464-2487.

Iris, Ç., Christensen, J., Pacino, D., Ropke, S., 2018. Flexible ship loading problem with transfer vehicle assignment and scheduling. Transportation Research Part B: Methodological 111, 113-134.

Iris, Ç., Pacino, D., Ropke, S., 2017. Improved formulations and an adaptive large neighborhood search heuristic for the integrated berth allocation and quay crane assignment problem. Transportation Research Part E: Logistics and Transportation Review 105, 123-147.

Iris, Ç., Pacino, D., Ropke, S., Larsen, A., 2015. Integrated berth allocation and quay crane assignment problem: Set partitioning models and computational results. Transportation Research Part E: Logistics and Transportation Review 81, 75-97.

Jin, J. G., Lee, D. H., Cao, J. X., 2016. Storage yard management in maritime container terminals. Transportation Science 50, 1300-1313.

Levinson, M., 2016. The Box: How the Shipping Container Made the World Smaller and the World Economy Bigger. Princeton University Press, Princeton, NJ.

Li, Y., Chu, F., Zheng, F., Kacem, I., 2019. Integrated berth allocation and quay crane assignment with uncertain maintenance activities. 2019 International Conference on Industrial Engineering and Systems Management IESM, Shanghai, China.

Liu, C., 2020. Iterative heuristic for simultaneous allocations of berths, quay cranes, and yards under practical situations. Transportation Research Part E: Logistics and Transportation Review 133, 101814.

Malekahmadi, A., Alinaghian, M., Hejazi, S. R., Saidipour, M. A. A., 2020. Integrated continuous berth allocation and quay crane assignment and scheduling problem with time-dependent physical constraints in container terminals. Computers \& Industrial Engineering 147, 106672.

Notteboom, T., Rodrigue J. P., 2009. The future of containerization: Perspectives from maritime and inland freight distribution. GeoJournal 74, 7-22.

Notteboom, T., Yang Z., 2017. Port governance in China since 2004: Institutional layering and the growing impact of broader policies. Research in Transportation Business \& Management 22, 184-200. 
Razouk, C., Benadada, Y., Boukachour, J., 2019. Adapted Bin-Packing algorithm for the yard optimization problem. Bioinspired Heuristics for Optimization 774, 137-152.

Rodrigue, J. P., Notteboom, T., 2009. The terminalization of supply chains: Reassessing the role of terminals in port/hinterland logistical relationships. Maritime Policy \& Management 36, 165-183.

Stahlbock, R., Voß, S., 2008. Operations research at container terminals: A literature update. OR Spectrum 30, 1-52.

Steenken, D., Voß, S., Stahlbock, R., 2004. Container terminal operation and operations research: A classification and literature review. OR Spectrum 26, 3-49.

Tang, L. X., Zhao, J., Liu, J. Y., 2014. Modeling and solution of the joint quay crane and truck scheduling problem. European Journal of Operational Research 236, 978-990.

Wang, K., Zhen, L., Wang, S., Laporte, G., 2018. Column generation for the integrated berth allocation, quay crane assignment, and yard assignment problem. Transportation Science 52, 812-834.

Wang, T., Du, Y., Fang, D., Li, Z. C. 2020. Berth allocation and quay crane assignment for the trade-off between service efficiency and operating cost considering carbon emission taxation. Transportation Science 54, 1307-1331.

Yang, C., Wang, X., Li, Z., 2012. An optimization approach for coupling problem of berth allocation and quay crane assignment in container terminal. Computers \& Industrial Engineering 63, 243-253.

Zhang, X., Zeng, Q., Yang, Z., 2019. Optimization of truck appointments in container terminals. Maritime Economics \& Logistics 21, 125-145.

Zeng, Q. C., Yang, Z. Z., 2009. Integrating simulation and optimization to schedule loading operations in container terminals. Computers \& Operations Research 36, 1935-1944.

Zhen, L., Liang, Z., Zhuge, D., Lee, L. H., Chew, E. P., 2017. Daily berth planning in a tidal port with channel flow control. Transportation Research Part B: Methodological 106, 193-217.

Zhen, L., Xu, Z., Wang, K., Ding, Y., 2016. Multi-period yard template planning in container terminals. Transportation Research Part B: Methodological 93, 700-719.

Zhou, C., Lee, B. K., Li, H., 2020a. Integrated optimization on yard crane scheduling and vehicle positioning at container yards. Transportation Research Part E: Logistics and Transportation Review 138, 101966.

Zhou, C., Zhao, Q., Li, H., 2020b. Simulation optimization iteration approach on traffic integrated yard allocation problem in transshipment terminals. Flexible Services and Manufacturing Journal. Available at: https://doi.org/10.1007/s10696-02009393-5 